grounds of which were set forth in a previous paper.' road at the Boston session of the American Medical Assocjation. Thave been moved to repeat myself by the importance of the subject; by the unfortunate tendency of some new converts to go to extremes that tend to bring back all the old confusion; and by the misleading use to which a garbled extract from my own plea for conservatism has been put.

'The forces of right and of seience must not suffer themselves to be divided. 'The American Medical Association through THE Jolikxal and through the Council on Pharmacy and Chemistry, has well nigh accomplished what seemed at one time to be a hopeless task. No one will claim that the Council is infallible; all must admit its ability, its sincerity, its integrity, and its desire to be just. It js pursuing the right course and we can afford to await developments. Abore all we must hold up its hands. We must likewise avoid disarranging its plan of campaign by ill-devised sorties. at the wrong time and place and against the wrong persons.

\section{A NEW BLOODLESS METHOD OF AMPUTAT- ].NG THE ANUS AND RECTUM.}

\section{F. W. DUDLEY, M.D.}

Associate l'rofessor of Surgery, P. I. Medical School; Attending Surgeon St. Yaul's llospital. MIAILA, P. I.

The following operation which I. have devised has been used many times with excellent results. It is applicable to all cases of prolapse of the anus and rectum in which amputation is advisable. It is of value in (1) prolapse of the ants and rectum combined. with ulcer, when the bowel is thickened or indurated; (2) irredu(cible gangrenous or sloughing prolapse; (3) organic stricture; ( 4 ) adhesjons preventing reduction; (5) neoplasms involving the entire thickness of the intestinal wall, and (6) in procidentia due to organic stricture, in which the stricture has reached the lowest point of the prolapse, the whole may be excised, and thus the stricture and procidentia. cured at the same time. It is not intended that this operation take the place of sigmoidopexy or colopexy.

\section{JPLPARATION OF TIE PATIENT.}

In this, as in other operations on the rectum and anus, time spent in the proper preparation of the patient will add much to the success of the operation and to the patient's comfort subsequent to the operation. A few days' rest on the part of the patient is advisable before such an operation, when possible. He should remain on a very simple and moderate diet, the bowels being kept quite free, and he should drink freely of water. Thirtysix hours before operation two ounces of castor oil should be given. The lower bowel should be well washed out the night before and no enema given on the morning of operation.

\section{TECHNIC OF THE OPERITION.}

The patient is placed in the lithotomy position, with the buttocks well elevated. The sphincter is dilated and the bowel pulled well down by means of three forceps which are applied to the intestine. A little manipulation will enable one to work down all the redundant bowel. The rectum is packed with a long strip of gauze,

1. Cohen, s. S.: "The Limits of Proprietorship in Materia Medica," THe forlexal, 1907, xlviii, p. 195. about $6 \mathrm{~cm} .(21 / 4$ in.) in wilth. The rlevation of the buttocks allows the small intestine to gravitate back in the pelvis, and when the prolapse consists of more than three inches of bowel or there exists an archocele this step is important. If the small intestine be between the two eylinders of the prolapsed bowel it can easily be palpated between the thumb and finger and pushed up.

The protruded bowel js again well washed with soap and water; mercuric chlorid, 1 to 2.000 , and sterile water. T'wo long Kocher or. Ochsner mouse-toothed forceps are applied to the anterior wall of the prolapsed bowel in its long axis, one-blade in the rectum and the other above, from the folded margin up to within $3 \mathrm{~mm}$. $(1 / 8$ in.) of the skin surface, including both cylinders of the gut. 'These forceps are applied parallel about $1 \mathrm{~cm}$. ( $3 / 8$ in.) apart. . Both cylinders of the bowel (all the tissue grasped by the forceps) are divided between them up to within $2 \mathrm{~mm}$. (1/16 in.) of the skin margin. A catgut suture is then placed just beyond the toe of the right pair of forceps.

A hemorrhoidal clamp is applied beyond the toe of the pair of forceps to the left, the toe of the clamp pointing to the operator's left and grasping from 1.5 to $2 \mathrm{~cm}$. ( $1 / 2$ to $3 / 4$ in.) of the circumference of both folds of intestine, close to but not including the skin. 'The for(') the clamp is cut away by shears about $3 \mathrm{~mm}$. ( $1 / 8$ in.) from the clamp and the remaining tissue is seared by an electric soldering iron or other cautery, after first protecting the anus and surrounding skin with a shield made of asbestos cardboard or sheet lead. The tissue anbraced between the blades of the clamp is seized by the thumb and index finger of the left hand, the clamp removed and the two layerrs of intestine, now seared and axlherent, are sewn together by a lock stitch, using No. 2 chromic catgut. The suture should be sufficiently long to ontinue without interruption all the way round the margin of the anus, and the end after the first knot left long. A long straight round needle should be used. The ascistant holds the suture taut while the operator again applies 'the clamp and cautery, after which the suturing is again resumed and the process continued until the entire circumference of the bowel has been traversed, the two ends of the catgut then being tied.

No particular attention is paid to the vessels of the meentery. The sutures may be applied before the removal of the clamp and immediately tightened on its removal, or on the removal of the clamp instead of seizjng the tissues with the thumb and forefinger they may be caught with one or two mouse-toothed hemostatic forceps and the sutures applied and the forceps removed. 1 profer the first mentioned method. 'The entire operation can be completed in from fifteen to twenty minutes or less.

If the prolapsed bowel is more than three inclses. in length care should be taken not to include a knuckle of the sinall intestine in applying the clamp. To avoid this acrident, in addition to the measures spoken of in the foregoing, each bite of the cylinders of intestine should he examined between the thumb and index finger before it is grasped by the clamp. The presence of small intestime or omentum is easily detected and one meets with no trouble in crowding it upward with the examining fingers if the patient is in the proper position. In these cases several hemostatic forceps will need to be applied in turn when making the first or longitudinal incision. After the operation is completed the gauze is removed from the rectum. 
The dressing consists of sterilized vaselin and a few siguares of gauze helr in place with a $T$ bandage. No tube or other dressing is placed in the rectum. As a rule no pain is experienced; if there is any, one hypodermic injection of $1.4 \mathrm{mg}$. ( $1 / 5 \mathrm{gr}$.) morphin given as soon as the patient complains will he all that is required.

In these operations, as in hemorrhoid operations, burning the skin should be avoided. Such burns are extremely painful and the patient will often complain bitterly of them long after he is entirely well from the operation.

\section{AFTER-TREATMENT.}

The after-treatment consists of a limited quantity of liquid or light diet for seren days. An attmpt was formerly made to confine the bowcls by means of opium until the eighth day. when they were moved without pain. In several cases the bowels moved voluntarily on the second and third days without pain or subsequent tromble resulting therefrom. The bowels are now moved in all these cases on the third day, two ounces of castor oil lking given. T'Tre patient is allowed up and about thereafter and the bowels made to move daily.

It is practically impossible to infect the peritoneal cavity by this methor. not an inconsiderable advantage when operating in this region. There is no narrowing of the anal orifice. In cases in which this seems desirwhle three or four longitudinal sears, $3 \mathrm{~mm}$. (1/8 in.) in width, of the mucous membrane of the gut, after the operation is completed, will accomplish this. In these cases the wound usually is thoroughly healed about the tenth day and the patients are discharged from the hospital fourteen days after operation.

\section{THE RELATIVE MERITS OF 'THE OPERA-} TIONS FOR HEMORRHOIDS:*

\section{J. D. SINGLFI, A.M., M.D.}

Surgeon to the Pittsburg IIospital: Associate Professor of surgery and clinical Surgery. Iniversity of Pittsburg: Director of Magee Pathologieal Institute, Merey Hospital. PITTSBLRi, PA.

Is there a mortality attached to any of the classical operations for hemorrhoids? Undoubtedly there is. A word of protest against the rather commion statement. by surgeons at least, that the mortality of a given operation is "practically nil." However small, there is a definite mortality for any surgical procedure to be weighed in the balance with the risk to life if no operation is done.

With special reference to the mortality and the sulsm sequent condition of the patient, 1 wish to direct attention to a consideration of the relative merits and demerits of the three well-recognized types of operation for hemorrhoids: (1) the ligature method, (z) the Whitehead operation, and (3) the clamp and cautery operation. They are too well known to require description.

THE LIGATURE METHOD.

The pathologic condition about the lower end of the rectum in hemorrhoids--dilated, elongated and tortuous veins, often filled with simple or infective thrombi -and the impossibility of securing an operative field cren approximately free from bacteria, afford excellent grounds for anticipating an occasional serious postoperative complication which may and occasionally

* Leard before the Pitfsburg Acadamy of Medicine, May 12, 1008. does result in death. The puncture of a needle or a snip of the scissors can readily carry the Bacillus coli communis (whose function as an infective agent in all parts of the body is being recognized more and more) or other pathogenic bacteria into a vein and produce an infectious thrombophlebitis with subsequent embolism and death. Granted a clean field, the same process may be set up, for the thrombi in the hemorrhoidal veins are frequently already infected, presumably with the $B$. coli communis; and, granted that the thrombi are simple non-infected clots, such an embolus may result seriously.

That these dangers are not purely theoretic ones I an convinced from having observed one fatal case of premia and a number of cases of simple embolism following this apparently simple operation in the hands of capable and clean operators. In the cases in which siunple embolism has been observed the emboli fortunately liave lodged in the reins of the leg. but they may just as readily find a more vital spot.

There is certainly a definite, though low, mortality for this operation in the best hands, and it should be discarled in faror of other procedures, provided they promise less risk to life.

\section{THE WIITEIIEAD OPERATION.}

This is a most attractive method from the standpoint of the operator. It appeals to him as a more complete and exact surgical procedure in that it remores by nice dissection the entire pile-bearing area and leaves a neatly closed wound. There can be no doubt, however, but that the same possibilities for danger exist in this operation as have been pointed out for the ligature method with the same definite. mortality as an immediate result.

The common objection to the operation is based on the severity of the hemorrhage in patients already more or less debilitater by loss of blood. Improperly performed, this is a valid objection, but properly carried ont it does not hold. Severe hemorrhage is produced by dissecting up the mucons mombrane containing the piles about the entire circumference of the rectum before applying the sutures. If the dissection-is carried up beyond the lerel of the hemorrhoids at but one point and the mucous membrane is divided and immediately" sutured to the skin edge, thus controlling hemorrhage at that point, and if this be carried out step ly step completely around the rectum the loss of blood will be slight.

The ultimate results of this operation are excellent, as a rule, but they are by no means uniformly so. In a certain number of cases the patients levelop stricture of the anus of greater or less severity, a most distressing condition. This results from the contraction of an annular cicatrix which it is impossible to avoid, for complete primary union practically never occurs. On the other hanil. some of the patients have incontinence of feces from interference with the nerve supply of the sphincter. In either case the patient has male a poor 'xchange for his hemorrhoids.

The real objections, then, to this operation, which slould far ontweigh its operative nicety, are (1) the langer of simple or infective embolism. (2) the risk of stricture, and (3) the risk of incontinence.

\section{TIE ClaMP AND CaUTEIr OPERATION.}

If the details of this operation, as adrocated bv Ochsner, are strictly adhered to, it is, in my opinion, free from the oljections pointed out for the ligature and 